\title{
Development of the Separate Air-Supply Type of Pressurization Smoke Control System for the Stairwells of High-Rise Buildings in Korea
}

\author{
Jung-Yup Kim*, Hyun-Joon Shin, Chan-Sol Ahn, Ji-Seok Kim, Sang-Hyun Joo \\ Fire Research Center, Korea Institute of Civil Engineering and Building Technology, Goyang, Korea \\ Email: "jykim1@kict.re.kr, hjshin@kict.re.kr, chansole@kict.re.kr, gorapadk@kict.re.kr, jsh30@kict.re.kr
}

Received 2 July 2014; revised 2 August 2014; accepted 2 September 2014

Copyright (C) 2014 by authors and Scientific Research Publishing Inc.

This work is licensed under the Creative Commons Attribution International License (CC BY). http://creativecommons.org/licenses/by/4.0/

c) (i) Open Access

\begin{abstract}
The pressurization smoke control system has been commonly used as a smoke control system at the emergency stairs of high-rise buildings. However, a higher possibility of overpressure between the lobby and the accommodation or pressure drop in the lobby could lead to failure in achievement of the purpose of pressurization system, particularly when supplying the leakage and supplementary air flow through one air-supply path at a time. To improve this particular issue, the devise configurations, as well as the different ways to supply the leakage and supplementary air flow through the different flow passages have been proposed. The performance of the trial product was evaluated on the test bed, ultimately providing a safe evacuation environment if high-rise buildings fired.
\end{abstract}

\section{Keywords}

Pressurization System, Smoke Control, High-Rise Building, Evacuation Stairwell, Field Experiment

\section{Introduction}

With increased advancement and integration of the cities, the demand for large-scale, high-rise and complex buildings has been on the rise, and the number of buildings vulnerable to fire has also increased. In this connection, the effective measure to prevent firing is urgently needed. In particular, the importance of smoke control system has been highlighted in the recognition of smoke as the main cause disturbing the evacuation and fire

\footnotetext{
*Corresponding author.
} 
fighting activities, as well as the biggest threat to human life during fire.

In case of fire in high-rise buildings, stairwell must be tenable by preventing smoke from entering into stairwell which is a primary vertical evacuation route in order to safely evacuate occupants from the building. The stairwell pressurization method is one of the key smoke control methods, which is currently equipped in the stairwell of high-rise buildings. This method brings air from outside into stairwell through a dedicated fan to increase the pressure of stairwell, ultimately preventing smoke from entering the stairwell [1].

The stairwell pressurization method began to develop in earnest since 1980s and its key design guidelines were proposed in 1990s. Clark and Buckley [2] had explained how this stairwell pressurization method was adopted and the whole process from guideline proposal to its application expanded to buildings. Tamura [3] examined the characteristics and the type of each stairwell pressurization method and conducted an experimental analysis on key factors in designing the system. Tamura [4] conducted a real-scale experiment at a 10-story experimental fire tower to evaluate the performance of various overpressure controls applicable to stairwell pressurization system.

Recent studies consider the ways to improve the performance by conducting a real-scale experiment and a numerical analysis on the stairwell pressurization system. Wang and Gao [5] evaluated the performance depending on the installation and operation condition of stairwell pressurization system in a 32-story complex high-rise buildings. Bellido et al. [6] also evaluated the performance of stairwell pressurization system installed in each 6 different high-rise buildings. Black [7] analyzed smoke diffusion when fired the 40-story building with stairwell pressurization system installed by using the differential model that combined each characteristic of the differential method to enhance the accuracy of analysis and the network model to be suitable for the analysis on the fire caused in a large space such as high-rise buildings. Stack effect occurred in the vertical shaft of high-rise buildings during the winter season, which exhibited a great effect on the pressurization system of stairwell and elevator, while Miller and Beasley [8] analyzed this stack effect by using a network model program, the CONTAM.

Based on these results, various countries propose the design criteria for smoke control system of emergency stairs in high-rise buildings using the stairwell pressurization system, as shown in Table 1.

In Korea, "fire safety standards of smoke control facilities in the special emergency stairs" of NFSC501A is proposed as one of the fire safety standards designed to ensure the smoke safety of high-rise buildings and to prevent the penetration of the smoke from entering the smoke-control zone. In line with this, the pressurization method of smoke control to increase the pressure inside the lobby between the accommodation and the stair using a smoke control blower and an air-supply damper shown in Figure 1 has been widely used in Korea. In the pressurization smoke control system of stairs, the pressure difference between the lobby and the accommodation has to be maintained within a certain range to prevent penetration of the smoke from entering the stair and to make it easier for evacuees to open doors. Therefore, the flap dampers and differential pressure control dampers have been adopted.

As described above, the key design criteria of the stairwell pressurization smoke control system for high-rise buildings being used in key countries including Korea were established in around 1980s to 1990s, and these were involved in the fire safety standards of each country. The countries have realized the importance of the stairwell pressurization smoke control system that protects stairwell from smoke; however, the recent relevant studies and reports have confirmed the failure of the existing stairwell pressurization smoke control system in

Table 1. Design criteria for smoke control system of emergency stairs by major countries.

\begin{tabular}{cc}
\hline Nation & $\begin{array}{c}\text { Fire safety standards } \\
\text { (smoke control system part) }\end{array}$ \\
The U.S. & NFPA 92A \\
Europe & IBC $(1022.9,909.20)$ \\
China & EN 12101-6 \\
Korea & GB 50045 (8.3) \\
\hline
\end{tabular}




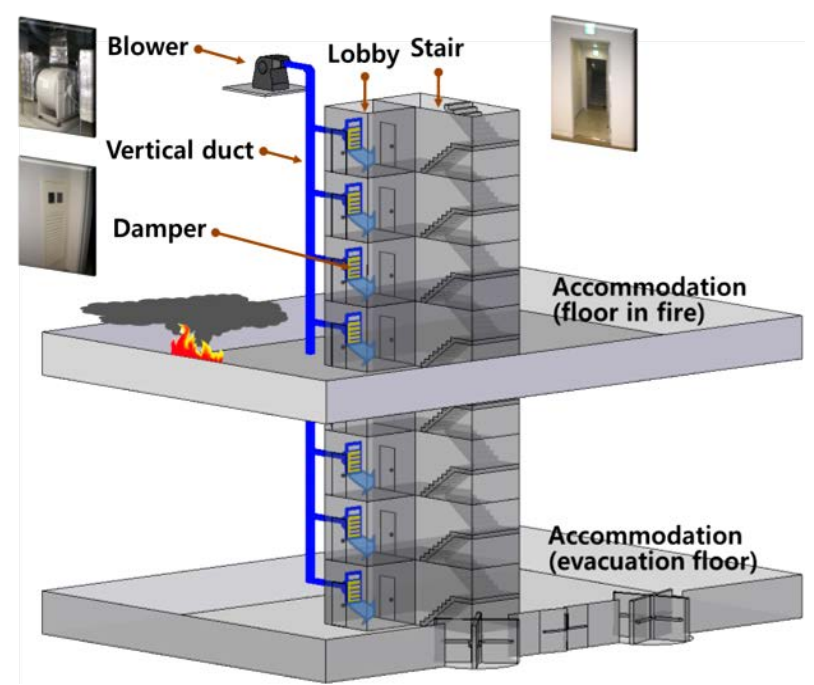

Figure 1. Conceptual diagram on the pressurization smoke control system of emergency stairs in Korea.

satisfying the criteria on safe evacuation set by each country. This implies the ineffectiveness of pressurization smoke control system currently installed at stairwell in offering a safe evacuation environment during fire [9] for the following facts: the analysis and system configuration in designing and operating the stairwell pressurization smoke control system relatively remains far behind the specific level [6]; the greater power is required from evacuees to open the exit in order to enter the stairwell [10]; and the proper pressure difference is not satisfied with too much excessive air supplies or evacuation exit opened [5].

In this study, a field evaluation was conducted on 2 high-rise buildings equipped with the pressurization smoke control system in order to evaluate the performance of the pressurization smoke control system of stairwell being installed and operated at the high-rise buildings. The results drawn from the field performance evaluation were analyzed; and as a result, a separate air-supply method has been proposed as a way to improve the existing pressurization smoke control system of stairwell. This new method is known to supply the air for leakage and supplementary through the different flowing paths. The design methodology of the separate air-supply method of pressurization smoke control, as well as the result of performance evaluation conducted in test bed have been proposed.

\section{Field Performance Evaluation on the Pressurization Smoke Control System of Stairwell}

\subsection{Field Experiment Methods}

In this study, a field evaluation was conducted on 2 high-rise buildings equipped with the pressurization smoke control system in order to evaluate the performance of the pressurization smoke control system of stairwell being installed and operated at the high-rise buildings. The indoor pressure in the accommodation, lobby and stairs during the operation of the smoke control systems has been measured and examined.

Figure 2 shows the air supply blower installed in each building, while the differential pressure control damper installed inside of the lobby is shown in Figure 3. The pressure sensor that measure the pressure generated inside through operating the smoke control system is shown in Figure 4.

\subsection{Results of Field Performance Evaluation}

\subsubsection{The Condition That All Doors Are Closed}

As shown in Figure 5(a), the indoor pressure was measured in the accommodation, lobby and stairs at the 2nd, 11th and 18th floors with all doors closed in 21-story Building. The performance resulted from the evaluation is shown in Figure 5(b) and Figure 5(c). Figure 5(b) indicates the indoor pressure variations in the accommodation, lobby and stairs depending on the time of measurement performed while operating the smoke control 


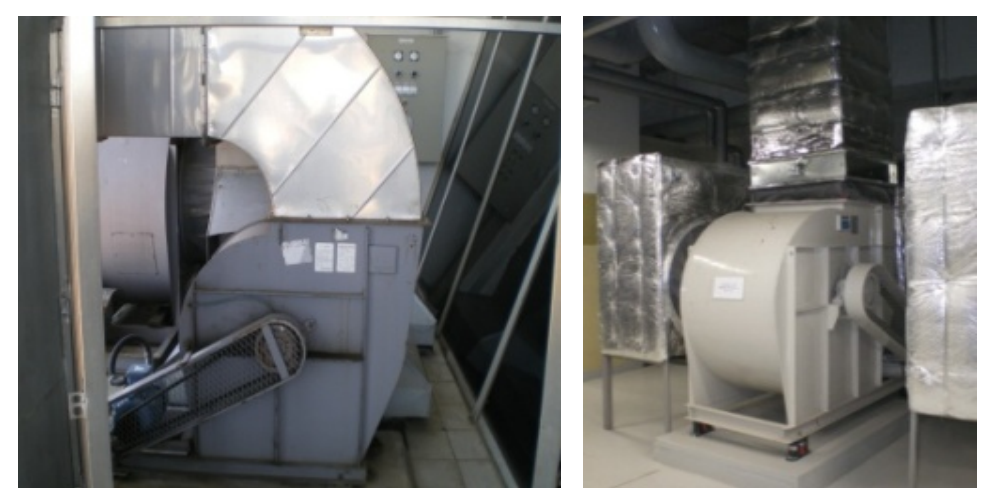

Figure 2. Air supply blower.

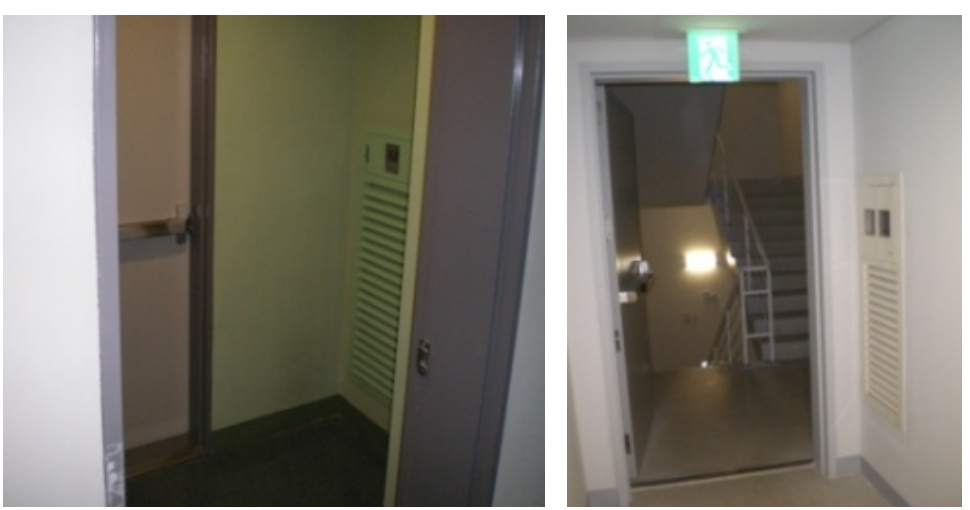

Figure 3. Lobby and damper.
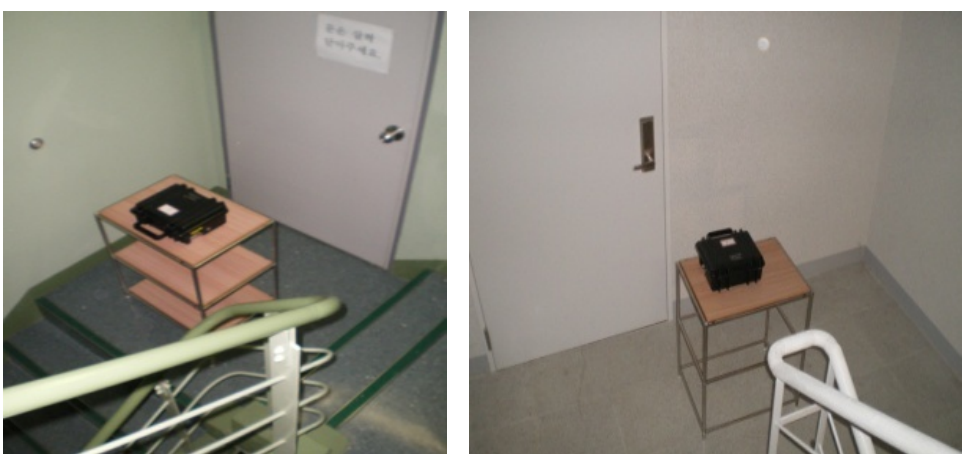

Figure 4. Pressure sensor.

systems. Figure 5(c) presents the pressure difference between the accommodation and the lobby.

As identified in the figures, the pressure difference between the accommodation and the lobby was $97 \mathrm{~Pa}$ on the 2nd floor after operating the pressurization smoke control system, whereas the pressure difference between the accommodation and the lobby at the 11th and 18th floors was recorded in the range of $112 \mathrm{~Pa}$ and $124 \mathrm{~Pa}$, showing much higher value compared to the design value, $50 \mathrm{~Pa}$. As mentioned above, the higher pressure difference generated between the accommodation and the lobby is much likely to be difficulty for evacuees to open the evacuation exit.

\subsubsection{The Condition That the Door of a Lobby Is Opened}

As shown in Figure 6(a), the indoor pressure was measured in the accommodation, lobby and stairs of the 3nd, 15th and 30th floors with the lobby door at the 1st floor kept opened in 31-story Building. Figure 6(b) and Figure 6(c) present the performance resulted from the evaluation. 


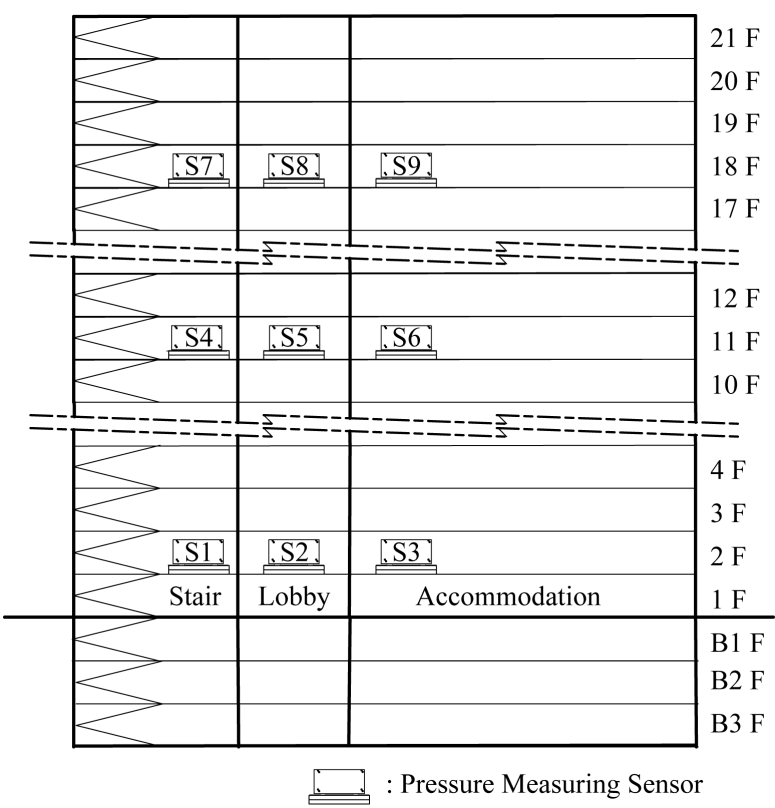

(a)

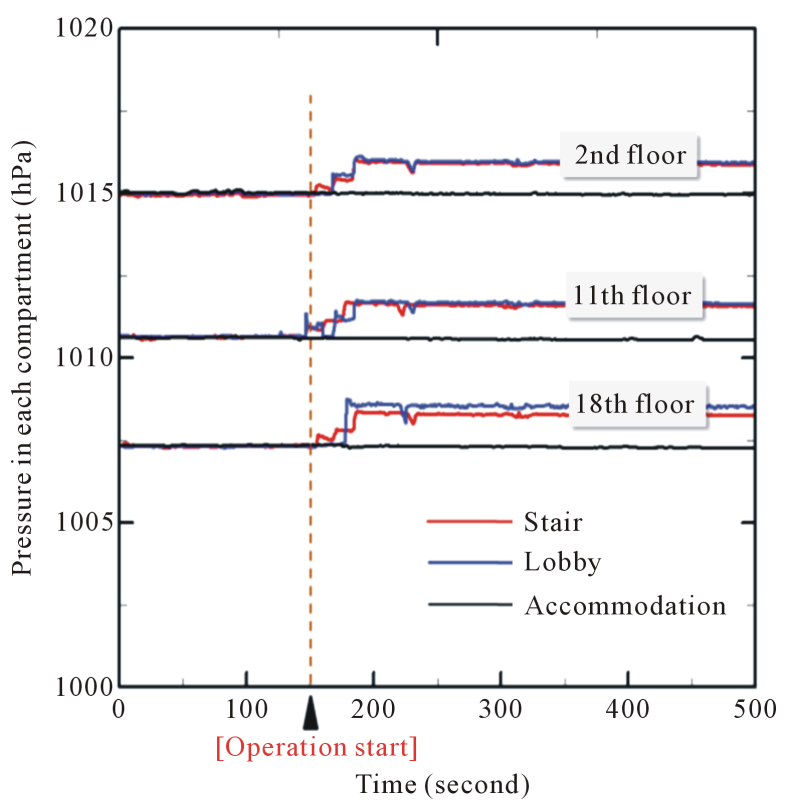

(b)

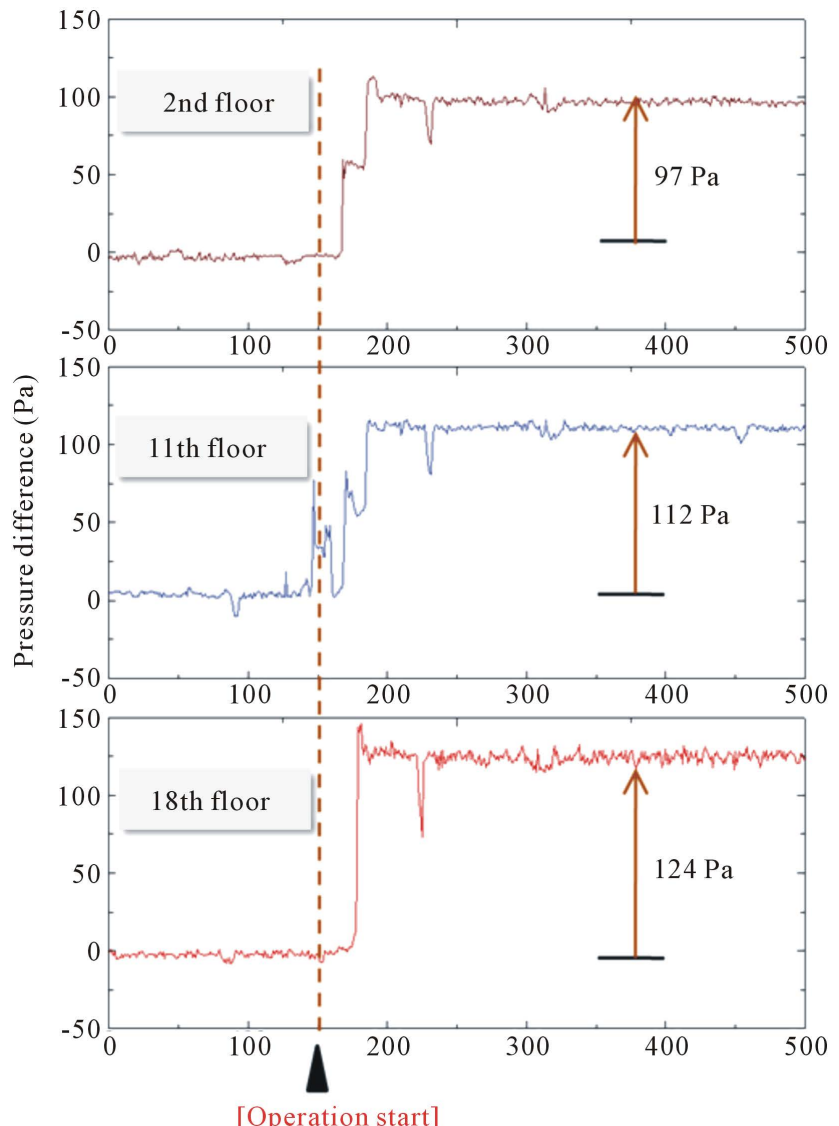

Time (second)

(c)

Figure 5. Field experiment results on the condition with all doors closed. (a) Schematic diagram of pressure sensor installation; (b) Pressure variations of each compartment; (c) Variations of pressure difference between the accommodation and the lobby. 


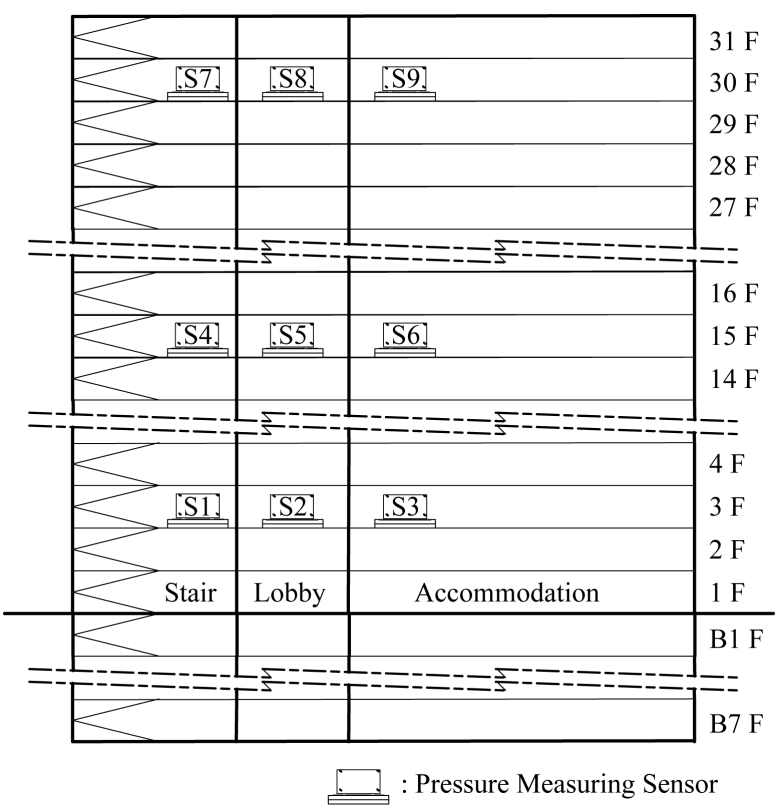

(a)

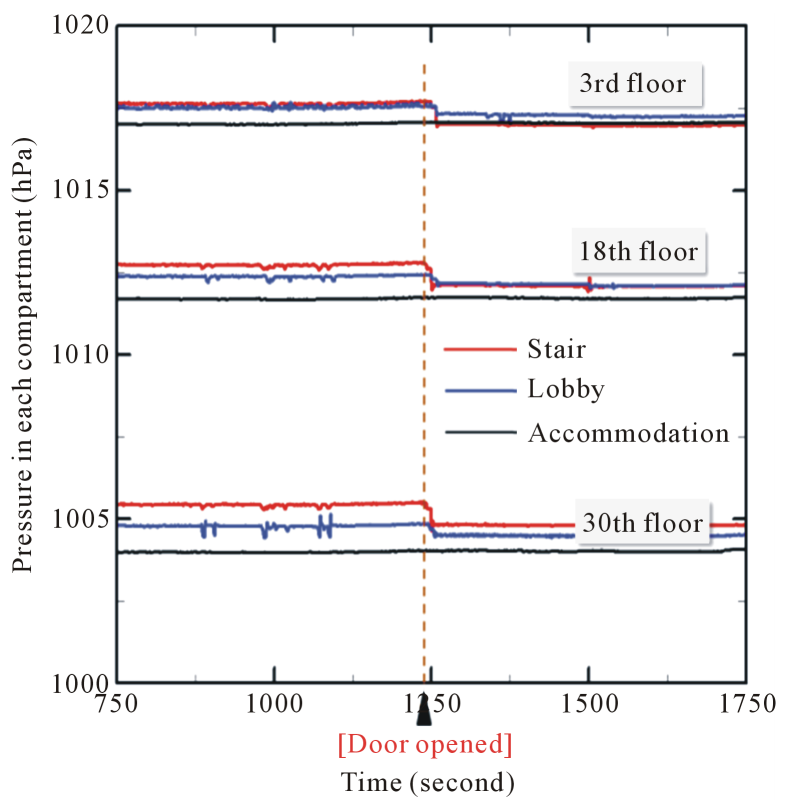

(b)

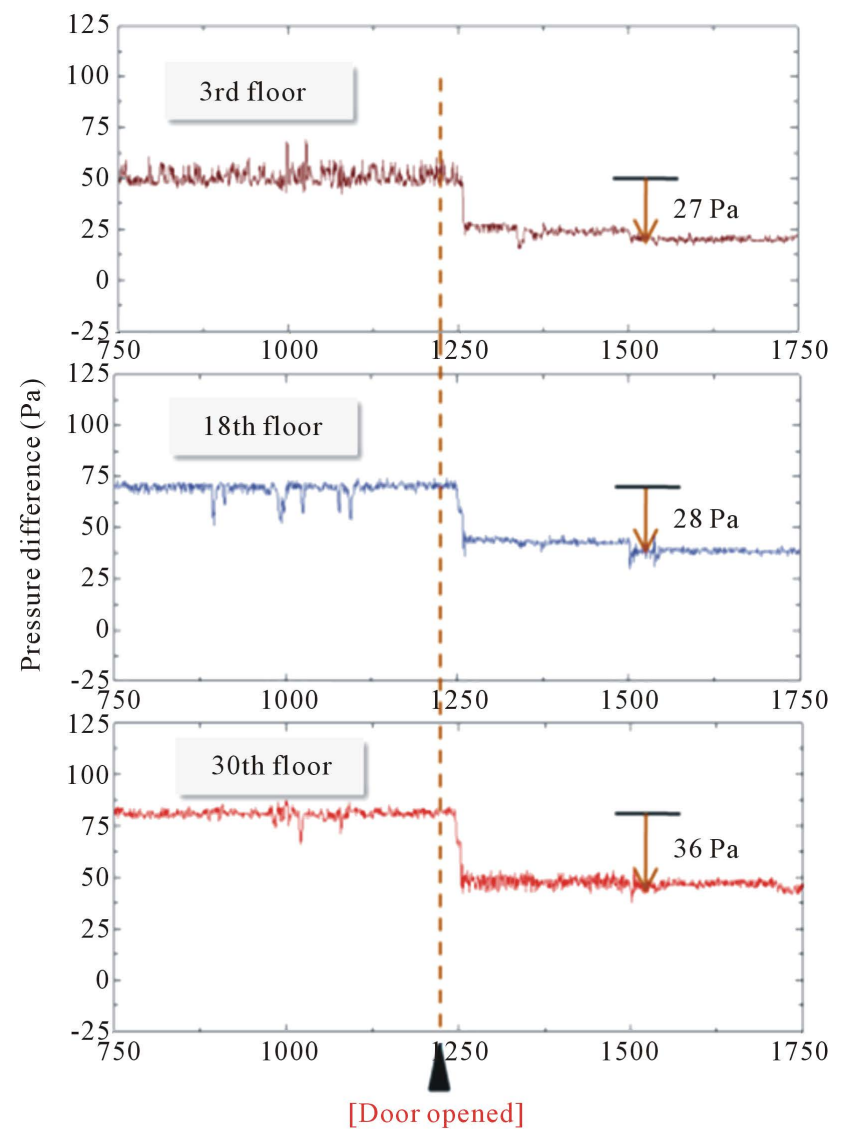

Time (second)

(c)

Figure 6. Field experiment results on the condition with the door of a lobby opened. (a) Schematic diagram of pressure sensor installation; (b) Pressure variations of each compartment; (c) Variations of pressure difference between the accommodation and the lobby. 
As identified in the figures, the pressure difference between the accommodation and the lobby was 48 Pa on the 3rd floor with all doors kept closed, while decreasing down to approximately 23 Pa with the door at a lobby left opened. The pressure difference at the 30th floor was decreased from about $82 \mathrm{~Pa}$ to $46 \mathrm{~Pa}$. As clarified above, the pressure of lobby and stairs at each floor may decline if the door at the lobby is kept opened.

\section{Development of the Separate Air-Supply Type of Pressurization Smoke Control System in the Stairwells}

As identified above, the issues associated with the existing pressurization smoke control systems are the pressure drop or overpressure between the accommodation and the lobby upon the opened or closed condition of the door. As to improve this issue, the devise configurations, as well as the different ways to supply the leakage and supplementary air flow through the different flow passages have been proposed as follows.

\subsection{Design Methodology of Separate Air-Supply Type}

In the separate air-supply type of pressurization smoke control system, the leakage air flow and the supplementary air flow are supplied separately to the lobby of each floor through the different flow passages. That is, the leakage air flow is supplied to the lobby on each floor through the leakage air flow supplying blower, the leakage air flow duct and the leakage air flow blade of damper. The supplementary air flow is supplied to the lobby on each floor through the supplementary air flow supplying blower, the supplementary air flow duct and the supplementary air flow blade of damper, as shown in Figure 7. If this concept of separate air-supply type is adopted, a reasonable amount of air could be supplied depending on the opened or closed condition of the doors at the lobby, as shown in Table 2.

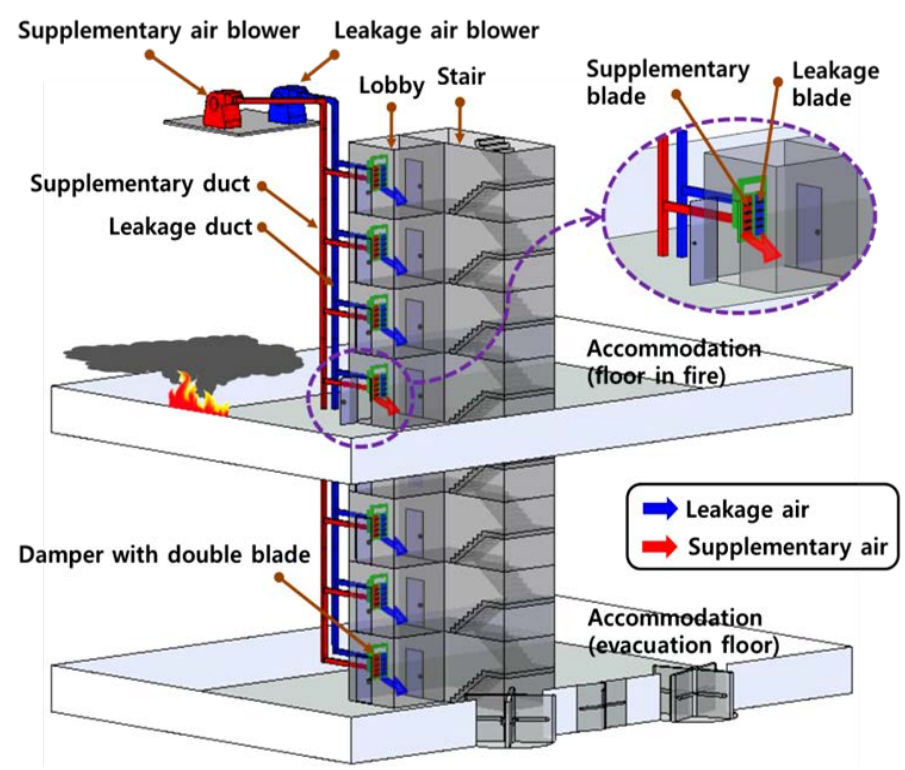

Figure 7. Conceptual diagram of the separate air-supply type of pressurezation smoke control system in the stairwells.

Table 2. Concept and effect of separate air supply.

\begin{tabular}{cll}
\hline Status of the door of lobby & Status of air supply to lobby \\
Closed & Only leakage air flow is supplied & $\begin{array}{l}\text { - Maintaining the proper pressure difference } \\
\text { Preventing overpressure between the lobby and the } \\
\text { accommodation }\end{array}$ \\
Opened & $\begin{array}{l}\text { - Forming a critical air velocity } \\
\text { Only supplementary air flow is supplied }\end{array}$ & $\begin{array}{l}\text { Preventing the leakage air from out flowing through } \\
\text { the opened door }\end{array}$ \\
\hline
\end{tabular}




\subsection{Development of Double-Blade Air Supply Damper}

To operate the pressurization smoke control system of separate air-supply type effectively, the air supply damper needs to be developed as a key component to provide and control the leakage and supplementary air flow depending on the pressure formation conditions. In this connection, the intelligent air supply damper of doubleblade type was developed in this study. As shown in Figure 8, the double-blade air-supply damper is composed of double blades for control of leakage and supplementary air flow rate in addition to pressure sensor, opening regulator and controller. In double-blade air-supply damper, the control blade of leakage air flow is connected to the vertical air duct for the leakage air flow supply, and the control blade of supplementary air flow is connected to the vertical air duct for the supplementary air flow supply. The double-blade air-supply damper is controlled to perform the open and close operation of the control blade for leakage air flow and the control blade for supplementary air flow, depending on the pressure differential $(\Delta \mathrm{p})$ of the lobby pressure $\left(\mathrm{p}_{\mathrm{L}}\right)$ and the accommodation pressure $\left(\mathrm{p}_{\mathrm{A}}\right)$, as shown in Table $3 . \Delta \mathrm{P}_{1}$ in the table is pressure differential which can distinguish whether the lobby door is opened or not (set to be $10 \mathrm{~Pa}$ in this study), while $\Delta \mathrm{P}_{2}$ is pressure differential which can prevent smoke from penetrating and prevent overpressure at the same time (set to be $50 \mathrm{~Pa}$ in this study).

\subsection{Installation of Test Bed and Performance Evaluation}

In this study, the separate air-supply type of pressurization smoke control system was installed at 5-story experiment building to conduct the real-scale performance evaluation. A floor plan of the experiment building being used as the test bed in this study is shown in Figure 9, whereas a conceptual diagram of installing the separate air-supply type of pressurization system is shown in Figure 10. As shown in the figures, a double-blade air supply damper was installed in the lobby at the 3rd, 4th, and 5th floors. A vertical duct was installed in the service shaft.

Air supply blower and control panel were installed in the equipment room on the rooftop. The pressure differential between the lobby and the accommodation of each floor, and opening ratio of the blades for the leakage air flow and the supplementary air flow were saved on the control panel in a real-time manner. Figure 11 shows the double-blade damper and the vertical duct installed in the lobby at the 3rd floor.

As mentioned above, the pressure differential $\left(\Delta \mathrm{P}_{2}\right)$ between the lobby and the accommodation was set at 50

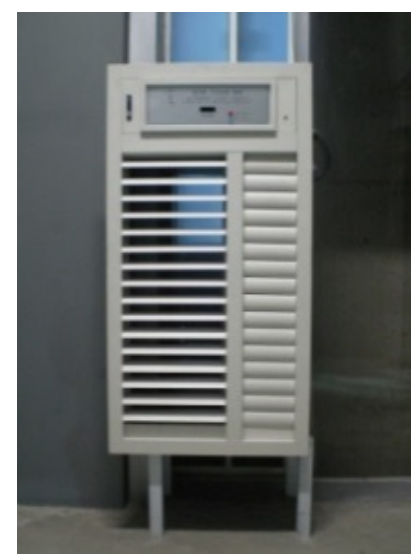

Figure 8. Complete view of double-blade air supply damper.

Table 3. Operating conditions of double-blade air supply damper.

\begin{tabular}{|c|c|c|c|}
\hline $\begin{array}{l}\text { Status of the } \\
\text { door of lobby }\end{array}$ & $\begin{array}{c}\text { Status of pressure differential }(\Delta \mathrm{P}) \\
\text { between the accommodation } \\
\text { and the lobby }\end{array}$ & $\begin{array}{l}\text { Operating condition of leakage } \\
\text { air flow blade }\end{array}$ & $\begin{array}{c}\text { Operating condition of } \\
\text { supplementary air flow blade }\end{array}$ \\
\hline Closed & $\Delta \mathrm{P}$ is higher than $\Delta \mathrm{P}_{1}$ & $\begin{array}{l}\text { - Opened in case } \Delta \mathrm{P} \text { is higher than } \Delta \mathrm{P}_{1} \\
\text { - } \mathrm{PID} \text {-controlled to maintain } \Delta \mathrm{P} \text { to be } \Delta \mathrm{P}_{2}\end{array}$ & Closed in case $\Delta \mathrm{P}$ is higher than $\Delta \mathrm{P}_{1}$ \\
\hline Opened & $\Delta \mathrm{P}$ is lower than $\Delta \mathrm{P}_{1}$ & - Closed in case $\Delta \mathrm{P}$ is lower than $\Delta \mathrm{P}_{1}$ & $\begin{array}{l}\text { Completely opened in case } \\
\Delta \mathrm{P} \text { is lower than } \Delta \mathrm{P}_{1}\end{array}$ \\
\hline
\end{tabular}




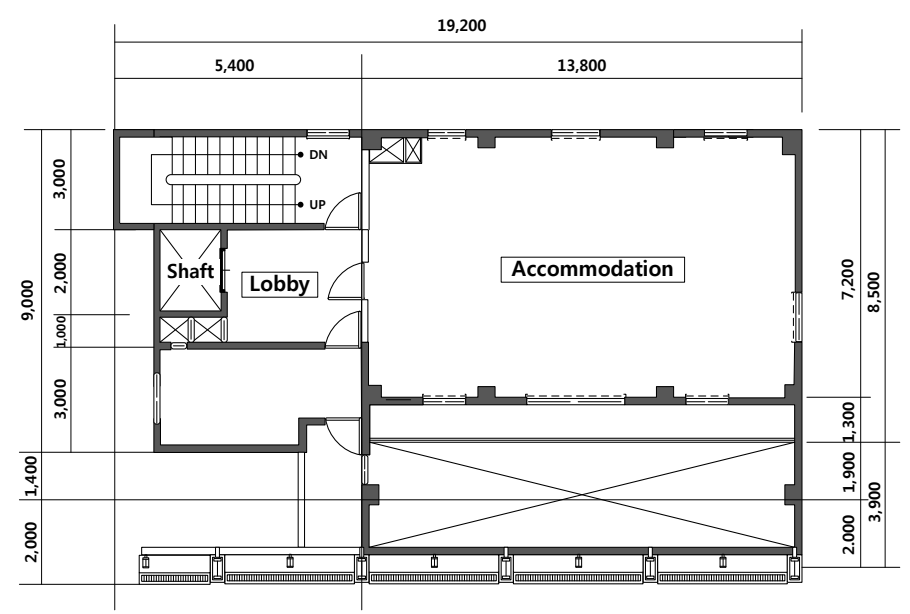

Figure 9. Floor plan of test bed.

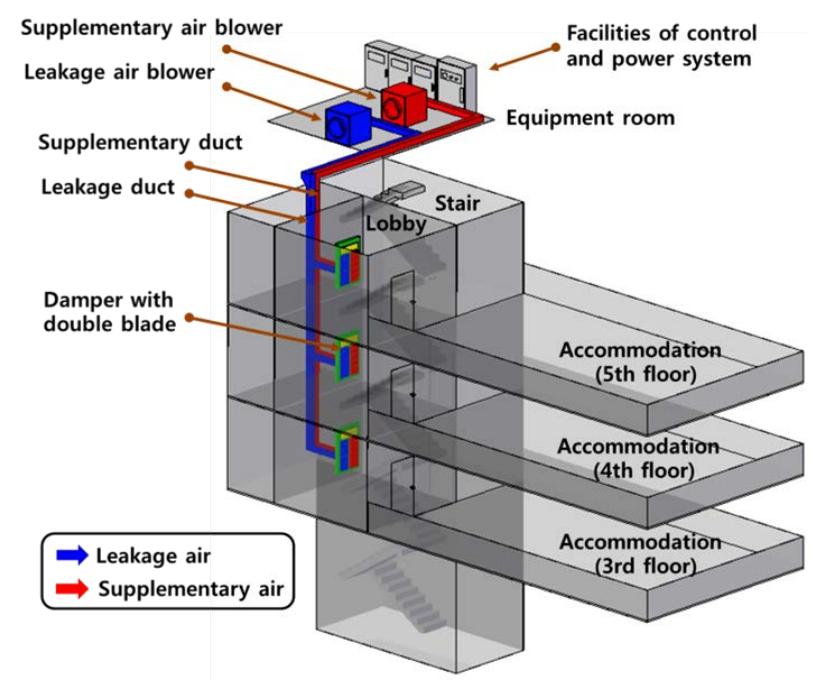

Figure 10. Conceptual diagram of installing the separate air-supply type of pressurization smoke control system in test bed.

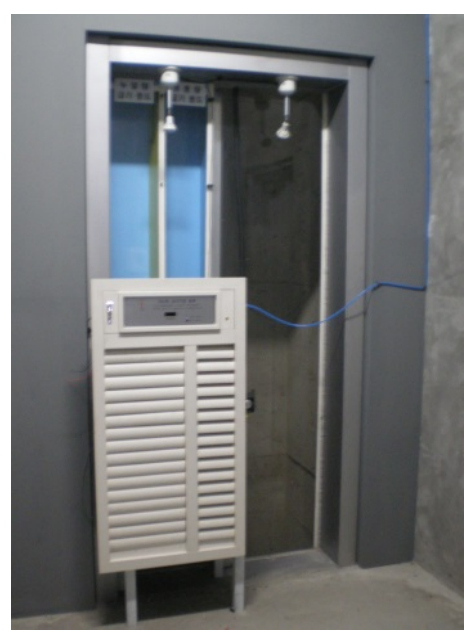

Figure 11. Damper with double blade and vertical duct installed in test bed. 
$\mathrm{Pa}$, the target of the blade for controlling the leakage air flow in the performance evaluation, whereas the pressure differential $\left(\Delta \mathrm{P}_{1}\right)$ between the lobby and the accommodation was set at $10 \mathrm{~Pa}$, the opening condition of blade for controlling the supplementary air flow.

The experiment was conducted while activating a separate air-supply type of pressurization smoke control system from 60 seconds after the experiment began. The emergency doors of the lobby on the 5th, 4th, and 3rd floors are kept opened and closed in order, from 180 seconds after the operation started. From this experiment, it is able to identify the results of pressure differential status and the operation performance of double-blade air supply damper on each floor under following two different conditions: 1 ) all of emergency doors on 3 floors are closed; 2) emergency doors on some floors are opened.

The results of performance evaluation conducted at the test bed are shown in Figure 12. Figure 12(a) shows the experimental results of the 5th floor, and Figure 12(b) and Figure 12(c) indicate the experimental results of the 4th and the 3rd floors respectively.
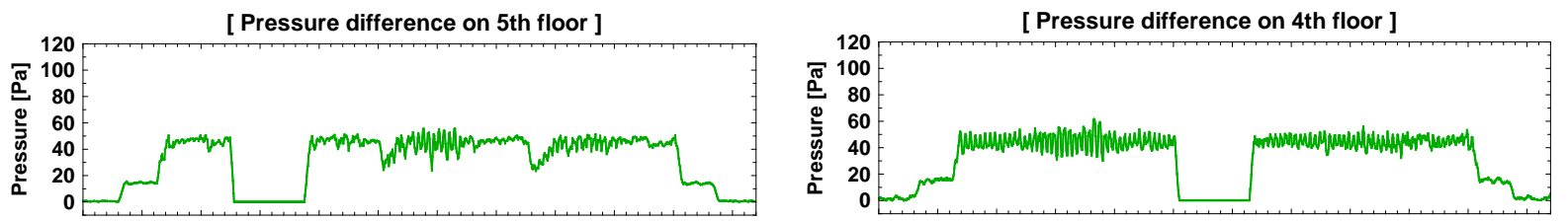

[ Leakage air flow blade on 5th floor ]
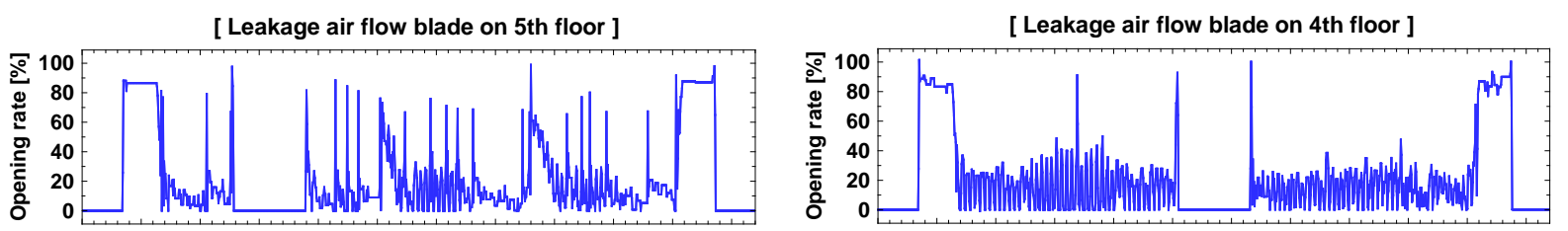

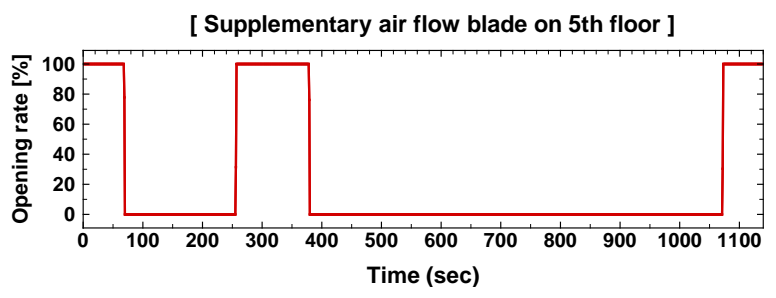

(a)

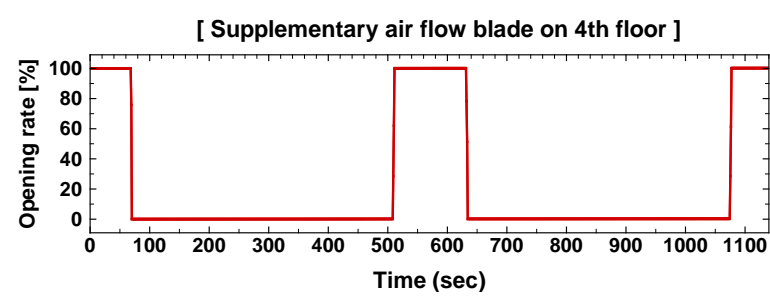

(b)
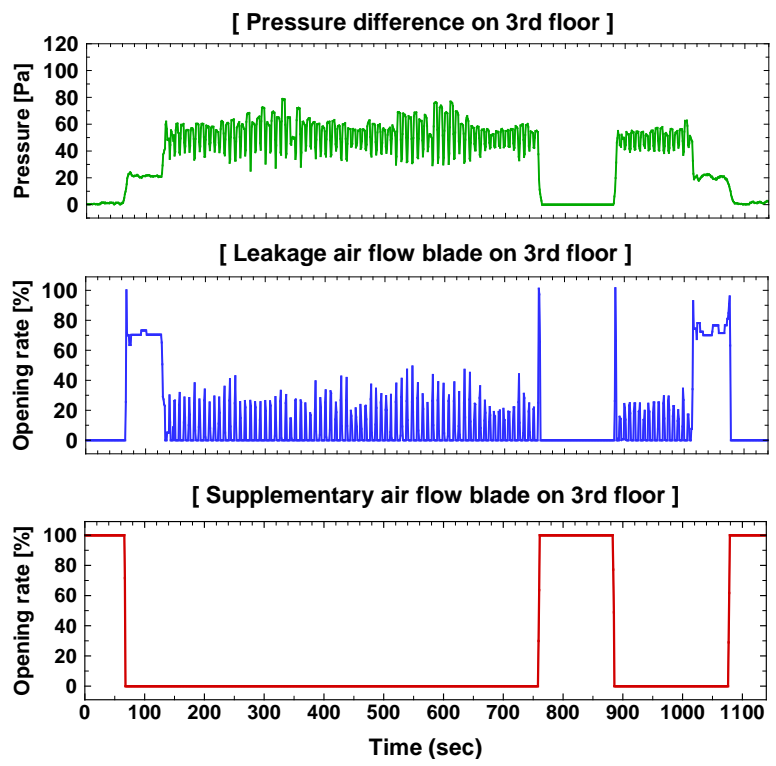

(c)

Figure 12. Experiment results in test bed. (a) 5th floor; (b) 4th floor; (c) 3rd floor. 
Upper graph in the figure shows the pressure difference between the lobby and the accommodation, while middle graph and bottom graph show opening ratio of leakage air flow blade and supplementary air flow blade in the air supply damper, respectively. From the experiment, it was found that if pressure difference between the lobby and the accommodation is under $50 \mathrm{~Pa}$, the leakage air flow blade in the air supply damper is opened more widely and the flow rate of leakage air which is supplied to the lobby increases. If the flow rate of leakage air increases and pressure difference between the lobby and the accommodation goes up over $\Delta \mathrm{P}_{2}$ later, opening ratio of leakage air flow blade is changed, resulting in adjusting the flow rate of leakage air and pressure difference between the lobby and the accommodation to be matched to the designed pressure differential $\left(\Delta P_{2}\right)$. If the door of the lobby is opened and the pressure of the lobby falls down to around " 0 ", the supplementary air flow blade is opened fully to supply enough supplementary air flow to form critical air velocity to the accommodation; at the same time, the leakage air flow blade in the air supply damper is completely closed to prevent leakage air flow from outflowing. The graphs from the experiment of each floor show the results from simultaneous experiments. Based on the graphs, it is confirmed that although the door of certain lobby is opened, it does not have any effect on other lobby, and each lobby is operated independently.

From the results of experiment, it is expected that the separate air-supply type of pressurization smoke control system will solves the issues associated with the overpressure between the compartments, including the pressure down with the lobby door opened. This system is also highly expected to effectively ensure the performance of smoke control system for a safe evacuation.

\section{Conclusions}

The importance of smoke control system has been highlighted in the recognition of smoke as the main cause disturbing the evacuation and fire fighting activities, as well as the biggest threat to human life during fire. In line with this, the pressurization smoke control system has been commonly used in Korea to prevent the penetration of the smoke from entering the emergency stairs.

The field evaluation on the operating performance of the pressurization smoke control system was carried out, targeting the multiple high-rise buildings currently in operation. However, a higher possibility of overpressure between the lobby and the accommodation or pressure drop in the lobby could lead to failure in achievement of the purpose of pressurization system, particularly when supplying the leakage and supplementary air flow through one air-supply path at a time.

In connection with the improvement of this problem, a key concepts of the separate air-supply type of pressurization smoke control system was introduced which separated the leakage air flow and supplementary air flow through different flow passages, and the operating principles and structure of the double-blade air supply damper were also suggested that was a key component for providing separate air supply effectively.

The trial product of a separate air-supplied pressurization system developed through the studies was installed at the 5-story test bed to conduct the performance test; and as a result, it is expected that the separate air-supply type of pressurization smoke control system will solve the issues associated with the overpressure between the compartments, including the pressure down with the lobby door opened. This system is also highly expected to effectively ensure the performance of smoke control system for a safe evacuation.

\section{Acknowledgements}

This study was conducted based on the relevant study, “Technology Development of Large Space Structures Have More than 3-Hour Fire-Resistance Rating and Smoke-Control/Evacuation in Fire”, a major project conducted by Korea Institute of Civil Engineering and Building Technology.

\section{References}

[1] Klote, J.H. and Milke, J.A. (2002) Principles of Smoke Management. American Society of Heating, Refrigerating and Air-Conditioning Engineers \& Society of Fire Protection Engineers, Atlanta.

[2] Clark, J.A. and Buckley, P.E. (1995) The Evolution of Pressurized Stairwells. ASHRAE Transactions, 101, $1001-1005$.

[3] Tamura, G.T. (1989) Stair Pressurization Systems for Smoke Control: Design Considerations. ASHRAE Transactions, 95, 184-192.

[4] Tamura, G.T. (1992) Assessment of Stair Pressurization Systems for Smoke Control. ASHRAE Transactions, 98, 1-7. 
[5] Wang, Y. and Gao, F. (2004) Test of Stairwell Pressurization Systems for Smoke Control in a High-rise Building. ASHRAE Transactions, 110, 185-192.

[6] Bellido, C., Quiroz, A., Panizo, A. and Torero, J.L. (2009) Performance Assessment of Pressurized Stairs in High-rise Building. Fire Technology, 45, 189-200. http://dx.doi.org/10.1007/s10694-008-0078-0

[7] Black, W.Z. (2010) COSMO-Software for Designing Smoke Control Systems in High-rise Building. Fire Safety Journal, 45, 337-348. http://dx.doi.org/10.1016/j.firesaf.2010.07.001

[8] Miller, R.S. and Beasley, D. (2009) On Strairwell and Elevator Shaft Pressurization for Smoke Control in Tall Building. Building and Environment, 44, 1306-1317. http://dx.doi.org/10.1016/j.buildenv.2008.09.015

[9] Lee, B. (2009) Strategies for Occupant Response to Fire in High-rise Residential Building. Fire Protection Association Australia and Arup Fire.

[10] Bennetts, I.D. and Thomas, I.R. (2007) Designing against Fire. Electronic Journal of Structural Engineering, 9-21. 
Scientific Research Publishing (SCIRP) is one of the largest Open Access journal publishers. It is currently publishing more than 200 open access, online, peer-reviewed journals covering a wide range of academic disciplines. SCIRP serves the worldwide academic communities and contributes to the progress and application of science with its publication.

Other selected journals from SCIRP are listed as below. Submit your manuscript to us via either submit@scirp.org or Online Submission Portal.
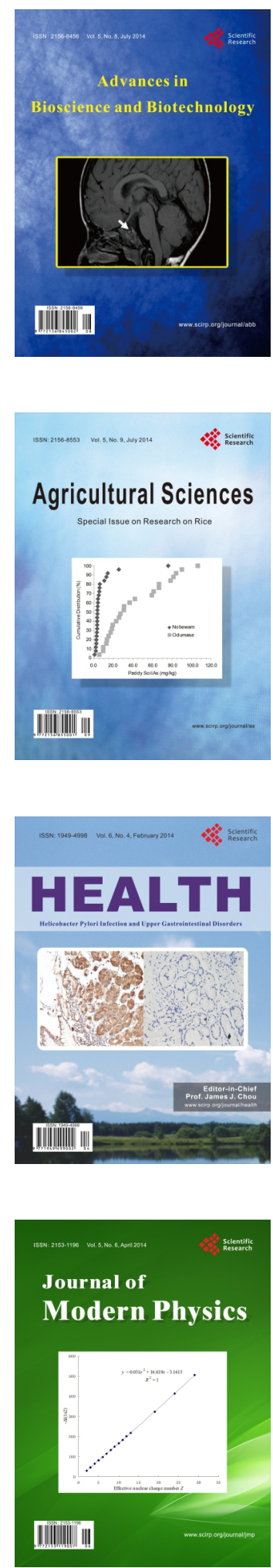
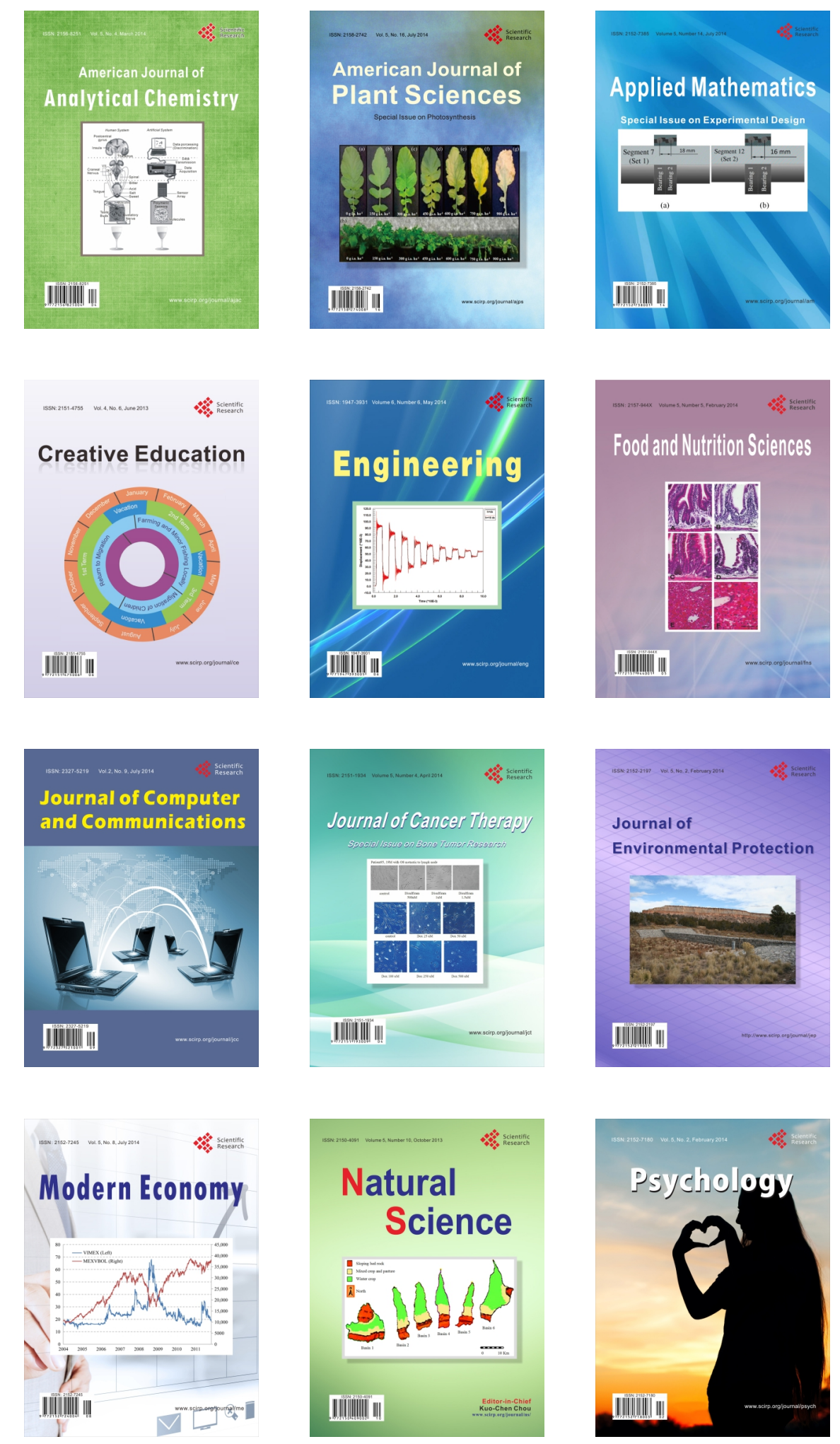